\title{
Trends in Diabetes Management Among US Adults: 1999-2016
}

\author{
Michael Fang, PhD®
}

Welch Center for Prevention, Epidemiology, and Clinical Research, Johns Hopkins University, Baltimore, MD, USA.

BACKGROUND: Updating national trends in diabetes management is important for identifying areas of progress and remaining gaps in diabetes care.

OBJECTIVE: Evaluate trends in diabetes management. DESIGN: Three nationally representative, serial crosssectional surveys (National Health and Nutrition Examination Survey [ $n=5800$ ], National Health Interview Survey [ $n=48,519]$, and Behavioral Risk Factor Surveillance System [ $n=741,497])$ were used to estimate trends in diabetes management from 1999 to 2016.

PARTICIPANTS: Non-pregnant US adults (aged $\geq$ 18 years) diagnosed with diabetes.

MAIN MEASURES: American Diabetes Association's general recommendations for glycemic and cardiovascular risk factor control, medication usage, physical activity, preventive practices, and dietary intake.

KEY RESULTS: From 1999 to 2016, the proportion of US adults with diabetes who attained glycemic control (HbAlc < 7.0\%) followed a quadratic trend $(49.6 \%$ in $1999-2004$ to $58.6 \%$ in $2005-2010$ to $55.8 \%$ in $2011-$ 2016, $P<0.05$ for trend). Control of blood pressure $(<$ 140/90 mmHg) and lipids (LDL cholesterol < $100 \mathrm{mg} / \mathrm{dl}$ ) increased by 6.6 and 18.7 percentage points, respectively $(P<0.05$ for trends). The proportion that attained glycemic, blood pressure, and lipid control followed a quadratic trend $(13.3 \%$ in $1999-2004$ to $24.8 \%$ in $2005-2010$ to $20.2 \%$ in $2011-2016, P<0.05$ for trend). Use of antidiabetic, antihypertensive, and statin medication among those who were eligible rose by $8.6,5.0$, and 24.0 percentage points, respectively ( $P<0.05$ for trends). Aerobic inactivity declined 7.1 percentage points, while adherence to aerobic activity ( $\geq 150 \mathrm{~min} /$ week) and resistance training ( $\geq 2$ times/week) recommendations grew 3.4 and 3.2 percentage points, respectively $(P<0.05$ for trends). Engagement in preventive practices (e.g., receipt of vaccinations) consistently increased for 6 out of 8 outcomes. However, the adherence to saturated fat $(<10 \%$ of total daily calories) and sodium $(<2300 \mathrm{mg} /$ day) recommendations fell by 6.5 and 5.2 percentage points $(P<0.05$ for trends).

CONCLUSIONS: Despite notable improvements, declines in glycemic control and adherence to dietary recommendations may be growing challenges in diabetes care.

KEY WORDS: diabetes mellitus; risk factor control; social disparities.

Electronic supplementary material The online version of this article (https://doi.org/10.1007/s11606-019-05587-2) contains supplementary material. which is available to authorized users.

Received May 29, 2019

Revised November 4, 2019

Accepted November 26, 2019

Published online January 2, 2020
J Gen Intern Med 35(5):1427-34

DOI: $10.1007 / \mathrm{s} 11606-019-05587-2$

(C) Society of General Internal Medicine 2020

\section{INTRODUCTION}

Over the past three decades, the prevalence of diabetes in the USA has grown substantially, particularly among $\mathrm{racial} / \mathrm{ethnic}$ minorities and those from low socioeconomic backgrounds. ${ }^{1-4}$ Left untreated, diabetes significantly elevates the risk of a host of micro- and macro-vascular complications, including cardiovascular disease and damage to the kidneys, feet, and eyes. ${ }^{5-7}$ Because of this, optimizing glycemic and cardiovascular risk factor control is critical for delaying and potentially preventing the onset of these negative health outcomes.

Each year, the American Diabetes Association (ADA) publishes a comprehensive set of evidence-based recommendations designed to optimize the management of diabetes. ${ }^{7}$ These are broad in scope and include treatment goals for glycated hemoglobin (HbA1C), blood pressure, and lowdensity lipoprotein (LDL) cholesterol (ABC goals), along with recommendations for medication usage, physical activity, preventive practices, and nutrition. Monitoring the rate at which these goals are achieved at a population level can help identify areas of improvement and gaps in diabetes care, which can inform the development of more effective public health policy and guide the allocation of research funds.

Prior studies using nationally representative data have shown that the proportion of US adults with diabetes meeting $\mathrm{ABC},{ }^{3,8-11}$ medication usage, ${ }^{3,12,13}$ and preventive practice goals $^{8,14}$ has increased significantly over time. Less is known about trends in the attainment of dietary and physical activity goals, though existing work suggests that rates are low and may have plateaued or even decreased over time. ${ }^{15-17}$ Few studies, however, have examined temporal trends using more recent data, considered multiple domains of diabetes management simultaneously, or explored social disparities in the attainment of these goals.

Using data from three nationally representative surveys, this study examined trends in diabetes management among US adults from 1999 to 2016. Analyses focused on five domains of diabetes care and investigated variation across education and race/ethnicity. 


\section{METHODS}

\section{Study Sample}

This study analyzed data from the National Health and Nutrition Examination Survey (NHANES), National Health Interview Study (NHIS), and Behavioral Risk Factor Surveillance System (BRFSS). Data from all three sources were collected from 1999 to 2016 and are representative of the noninstitutionalized, civilian population in the USA. Respondents were retained for the analysis if they reported being diagnosed with diabetes by a health professional, were 18 years in age or older, and were not pregnant. Further details for each study are available elsewhere. ${ }^{18-20}$

\section{Diabetes Management}

Drawing on clinical guidelines developed by the $\mathrm{ADA},{ }^{7}$ this study examined five sets of diabetes management outcomes (Table 1; Appendix 1).

Measurements from clinical examinations were used to determine the proportion of US adults with diabetes that met targets for HbAlc $(<7.0 \%)$, blood pressure $(<140 / 90 \mathrm{mmHg})$, and LDL cholesterol $(<100 \mathrm{mg} / \mathrm{dl})$. HbA1c values were calibrated to account for changes in laboratory methodology that may have artificially increased HbAlc levels. ${ }^{3}$ We also assessed the proportion that simultaneously attained all three $\mathrm{ABC}$ goals.

Information from medication container examinations was used to assess the proportion who were using antidiabetic, antihypertensive, and statin medications among those who were eligible based on ADA guidelines. Eligibility was defined as having uncontrolled diabetes $(\mathrm{HbA} 1 \mathrm{c} \geq 7.0 \%)$ for antidiabetic medication; having high blood pressure (self-reported or blood pressure $\geq 140 / 90 \mathrm{mmHg}$ ) for antihypertensive medication; and being $\geq 40$ years of age or having cardiovascular disease or risk factors for statins (see Appendix 1 for complete eligibility criteria).

Self-reported information related to physical activity performed for leisure was used to measure the proportion meeting recommended aerobic activity $(\geq 150 \mathrm{~min} /$ week of moderate aerobic activity, $\geq 75 \mathrm{~min}$ a week of vigorous aerobic activity, or some combination of both) and strength training ( $\geq 2$ times a week) targets. An additional indicator was used to examine the proportion that was physically inactive (no physical activity lasting at least $10 \mathrm{~min}$ during the week). We also assessed the proportion that simultaneously attained aerobic activity and strength training goals.

Self-reported information related to engagement in preventive practices was used to examine the proportion receiving dental (annual), foot (annual), and eye examinations (annual for those with self-reported retinopathy/biennial for those without self-reported retinopathy); vaccinations against influenza (annual), pneumonia (at least once ever), and hepatitis B (at least once ever); HbAlc tests (biannual); and formal diabetes education (at least once ever).
Table 1 Description of Diabetes Management Measures (National Health and Examination Survey (NHANES), National Health Interview Survey (NHIS), and Behavioral Risk Factor Surveillance System (BRFSS))

\begin{tabular}{|c|c|c|c|}
\hline $\begin{array}{l}\text { Management } \\
\text { outcome }\end{array}$ & $\begin{array}{l}\text { Respondents in } \\
\text { analysis }\end{array}$ & $\begin{array}{l}\text { Data } \\
\text { source }\end{array}$ & $\begin{array}{l}\text { Years } \\
\text { available }\end{array}$ \\
\hline \multicolumn{4}{|l|}{$\mathrm{ABC}$ targets } \\
\hline $\mathrm{HbA} 1 \mathrm{c}<7.0 \%$ & All & \multirow{3}{*}{ NHANES } & \multirow{4}{*}{$\begin{array}{l}1999 \\
2016\end{array}$} \\
\hline Blood pressure $<$ & All & & \\
\hline $140 / 90 \mathrm{mmHg}$ & & & \\
\hline $\begin{array}{l}\text { LDL cholesterol < } \\
100 \mathrm{mg} / \mathrm{dl}\end{array}$ & $\begin{array}{l}\text { Random morning } \\
\text { fasting half-sample }\end{array}$ & & \\
\hline \multicolumn{4}{|l|}{ Medication usage } \\
\hline $\begin{array}{l}\text { Antidiabetic } \\
\text { medication }\end{array}$ & $\begin{array}{l}\text { Respondents with } \\
\text { uncontrolled } \\
\text { diabetes }(\mathrm{Hb} \mathrm{A} 1 \mathrm{c} \geq \\
7.0 \%)\end{array}$ & NHANES & \multirow[t]{3}{*}{$\begin{array}{l}1999 \\
2016\end{array}$} \\
\hline $\begin{array}{l}\text { Antihypertensive } \\
\text { medication }\end{array}$ & $\begin{array}{l}\text { Respondents with } \\
\text { hypertension (self- } \\
\text { reported or blood } \\
\text { pressure } \geq 140 / \\
90 \mathrm{mmHg} \text { ) }\end{array}$ & & \\
\hline Statin medication & $\begin{array}{l}\text { Respondents who } \\
\text { were } \geq 40 \text { years of } \\
\text { age or had } \\
\text { cardiovascular } \\
\text { disease/risk factors } \\
\text { (see Appendix } 1 \\
\text { for complete list of } \\
\text { inclusion criteria) }\end{array}$ & & \\
\hline \multicolumn{4}{|c|}{ Physical activity targets } \\
\hline Aerobic activity & & NHIS & 1999 \\
\hline$<10 \mathrm{~min} /$ week & All & & 2016 \\
\hline$\geq 150 \mathrm{~min} /$ week & All & & \\
\hline Strength training & & & \\
\hline \multirow{2}{*}{\multicolumn{4}{|c|}{ Preventive practices }} \\
\hline & & & \\
\hline \multicolumn{4}{|l|}{ Annual examinations } \\
\hline Dental & All & NHIS & $\begin{array}{l}1999 \\
2016\end{array}$ \\
\hline Eye & All & NHIS & $\begin{array}{l}2002 \\
2008 \\
2016\end{array}$ \\
\hline Foot & All & BRFSS & $\begin{array}{l}1999 \\
2016\end{array}$ \\
\hline \multicolumn{4}{|l|}{ Vaccinations } \\
\hline Influenza (annual) & All & NHIS & $\begin{array}{l}1999 \\
2016\end{array}$ \\
\hline Pneumococcal & All & NHIS & $\begin{array}{l}1999- \\
2016\end{array}$ \\
\hline Hepatitis B & All & NHIS & $\begin{array}{l}2000- \\
2016\end{array}$ \\
\hline $\begin{array}{l}\text { Biannual HbAlc } \\
\text { test }\end{array}$ & All & BRFSS & $\begin{array}{l}1999 \\
2016\end{array}$ \\
\hline Diabetes education & All & BRFSS & $\begin{array}{l}2000 \\
2016\end{array}$ \\
\hline $\begin{array}{l}\text { Dietary targets } \\
<10 \% \text { total daily } \\
\text { calories from } \\
\text { saturated fats }\end{array}$ & All & NHANES & $\begin{array}{l}1999 \\
2016\end{array}$ \\
\hline $\begin{array}{l}<2300 \mathrm{mg} \\
\text { sodium/day }\end{array}$ & All & & \\
\hline $14 \mathrm{~g}$ fiber $/ 1000 \mathrm{kcal}$ & All & & \\
\hline $\begin{array}{l}<300 \mathrm{mg} \\
\text { cholesterol/day }\end{array}$ & All & & \\
\hline
\end{tabular}

Self-reported information from dietary recall interviews was used to determine the proportion that met recommended targets for the intake of saturated fat $(<10 \%$ of all calories), sodium $(<2300 \mathrm{mg} /$ day $)$, cholesterol $(<300 \mathrm{mg} /$ day $)$, and fiber ( $\geq 14 \mathrm{~g} / 1000 \mathrm{kcal}$ consumed). 


\section{Statistical Analysis}

This study focused on trends in diabetes management outcomes from 1999 to 2016 among US adults diagnosed with diabetes. All estimates were generated by pooling survey data together into three 6-year intervals (1999-2004; 2005-2010; 2011-2016) to improve precision. ${ }^{21}$ Tests for time trends, on the other hand, were performed using unpooled data, as recommended by recent analytic guidelines. ${ }^{22}$ All analyses were conducted using Stata 14.0 (StataCorp) and used recommended survey weights. A two-sided $P$ value of less than 0.05 was considered to indicate statistical significance.

Analyses proceeded in three general steps. First, we estimated the unadjusted proportion of the population that attained diabetes management targets over time. Time trends were tested using logistic regression models, with diabetes management targets being regressed onto survey year, entered as both a linear and quadratic term. As a sensitivity analysis, we repeated this analysis while controlling for sociodemographic characteristics (age, sex, race/ethnicity, and education) using predictive margins.

Second, we estimated the unadjusted mean level of four key clinical outcomes (HbA1c, blood pressure, and LDL cholesterol) in the overall population over time. Trends were assessed with linear regression models, regressing these continuous outcomes onto survey year (linear and quadratic).

Third, we considered heterogeneity in the attainment of diabetes management targets. Race and education-specific estimates were generated, and logistic regression models that interacted with survey year with sociodemographic characteristics were examined. Adjusted Wald tests were used to assess the statistical significance of these interaction terms. Because interactions between sociodemographic characteristics and quadratic time trends (e.g., education $\times$ time $\times$ time) were all non-significant, only interactions using linear time trends are presented here.

\section{RESULTS}

Table 2 presents the characteristics of US adults aged 18 or older diagnosed with diabetes. Across all three studies, there was an increase in the percentage of adults with diabetes with at least a high school degree. Within the NHIS and the BRFSS, racial/ethnic minorities and those older in age made up a growing proportion of adults who were diagnosed with diabetes.

The proportion of adults with diabetes that attained glycemic control followed a quadratic trend (Table 3, $P=0.001$ ), increasing from $49.6 \%$ (95\% CI 45.3-53.9) in 1999-2004 to $58.6 \%$ (95\% CI 55.2-62.0) in 2005-2010 before declining to $55.8 \%$ (95\% CI 52.6-58.9) in 2011-2016. On the other hand, there was a consistent increase in the proportion of adults with diabetes who met recommended targets for blood pressure (66.8 to $73.4 \%, P=0.002$ for trend) and LDL cholesterol ( 37.5 to $56.3 \%, P=0.02$ for trend). The proportion that achieved all three $\mathrm{ABC}$ goals followed a quadratic trend $(P=0.002)$, improving from 1999-2004 to 2005-2010 (13.3 to $24.8 \%$ ) before falling in 2011-2016 (24.8 to $20.2 \%$ ).

Similar changes were evident in the average level of these clinical measures (Fig. 1). During the study period, mean HbA1C decreased substantially from 1999-2004 to 20052010 (7.43 to $7.08 \%$ ) before rising in 2011-2016 (7.08 to $7.22 \%, P=0.001$ for trend). Meanwhile, there were nonlinear decreases in both mean LDL cholesterol (115.1 to $99.0 \mathrm{mg} / \mathrm{dl}$, $P \leq 0.001$ for trend) and systolic blood pressure (133.1 to $129.9 \mathrm{mmHg}, P=0.019$ for trend) and no change in diastolic blood pressure.

The use of prescription medication was high and rose substantially during the study period. The use of antidiabetic medication among those with uncontrolled diabetes increased by 8.6 percentage points ( 82.5 to $91.1 \%, P \leq 0.001$ for trend) and the use of statins among those who had CVD or CVD risk factors increased by 24 percentage points ( 31.9 to $55.9 \%, P \leq$ 0.001 for trend). The use of antihypertensive medication among those with hypertension followed a quadratic trend ( $P=0.001$ for trend), increasing from 1999-2004 to 20052010 (81.6 to $87.2 \%$ ) before declining slightly in $2011-2016$ (87.2 to $86.6 \%)$.

The attainment of physical activity goals grew during the study as well, though gains were more modest in size. From 1999-2004 to 2011-2016, the average amount of time US adults with diabetes spent on moderate aerobic activity increased from 86.4 to 103.3 min per week $(P \leq 0.001$ for trend; data not shown). Accordingly, the proportion that reached the aerobic activity target increased (27.5 to $30.9 \%, P \leq 0.001$ for trend) while the proportion that was aerobically inactive decreased (55.7 to $48.6 \%, P \leq 0.001$ for trend). The proportion that met strength training guidelines also increased (9.8 to $13.0 \%, P \leq 0.001$ for trend). The proportion that met both aerobic and resistance training goals was low, but increased by 2.1 percentage points during the study period (6.6 to $8.7 \%$, $P \leq 0.001$ for trend).

There were fairly consistent improvements in the engagement of recommended preventive practices. From 1999-2004 to 2011-2016, a growing proportion of adults with diabetes received annual dental examinations $(51.5$ to $54.2 \%, P \leq$ 0.001 for trend) and annual foot examinations (67.6 to $73.0 \%, P \leq 0.001$ for trend); received an annual vaccination for influenza (53.4 to $61.1 \%, P=0.005$ for trend) and a vaccination for pneumonia (39.8 to $51.4 \%, P \leq 0.001$ for trend) and hepatitis B (16.2 to $23.3 \%, P=0.004$ for trend); and tested their HbA1c levels at least twice a year $(69.9 \% \%$ to $73.7 \% \%$, $P \leq 0.001$ for trend). The two exceptions were eye examinations and diabetes education: the receipt of eye exams was high but remained unchanged, while the receipt of diabetes education increased slightly from 1999-2004 to 2005-2010 (51.9 to 54.5\%) before declining slightly in 2011-2016 (54.5 to $52.9 \%, P \leq 0.001$ for trend).

Conversely, trends in the attainment of dietary intake targets remained unchanged or declined during the study period. 
Table 2 Sociodemographic Characteristics of US Adults with Diagnosed Diabetes, 1999-2004 to 2011-2016

\begin{tabular}{|c|c|c|c|c|c|c|c|c|c|c|c|c|}
\hline & \multicolumn{4}{|c|}{ NHANES $(N=5800)$} & \multicolumn{4}{|c|}{ NHIS $(N=48,519)$} & \multicolumn{4}{|c|}{ BFRSS $(N=741,497)$} \\
\hline & $\begin{array}{l}1999- \\
2004\end{array}$ & $\begin{array}{l}2005- \\
2010\end{array}$ & $\begin{array}{l}2011- \\
2016\end{array}$ & $\begin{array}{l}P \\
\text { value }\end{array}$ & $\begin{array}{l}1999- \\
2004\end{array}$ & $\begin{array}{l}2005- \\
2010\end{array}$ & $\begin{array}{l}2011- \\
2016\end{array}$ & $\begin{array}{l}P \\
\text { value }\end{array}$ & $\begin{array}{l}1999- \\
2004\end{array}$ & $\begin{array}{l}2005- \\
2010\end{array}$ & $\begin{array}{l}2011- \\
2016\end{array}$ & $\begin{array}{l}P \\
\text { value }\end{array}$ \\
\hline \multicolumn{13}{|l|}{ Age $(\%)$} \\
\hline $18-44$ & 16.4 & 14.4 & 13.8 & 0.53 & 15.7 & 15.0 & 12.4 & \multirow[t]{4}{*}{$<0.001$} & 16.2 & 15.7 & 13.1 & \multirow[t]{3}{*}{$<0.001$} \\
\hline $45-64$ & 44.0 & 45.9 & 46.7 & & 44.6 & 47.3 & 46.0 & & 44.5 & 45.6 & 45.7 & \\
\hline \multirow{2}{*}{\multicolumn{12}{|c|}{$\operatorname{Sex}(\%)$}} & \\
\hline & & & & & & & & & & & & \\
\hline Male & 51.5 & 52.1 & 48.7 & 0.20 & 49.7 & 49.5 & 49.8 & \multirow[t]{2}{*}{0.88} & 48.9 & 50.6 & 50.3 & \multirow[t]{2}{*}{$<0.001$} \\
\hline Female & 48.5 & 48.0 & 51.3 & & 50.3 & 50.5 & 50.2 & & 51.1 & 49.4 & 49.7 & \\
\hline \multicolumn{13}{|c|}{ Race/ethnicity* $(\%)$} \\
\hline NH-White & 63.4 & 61.3 & 59.2 & 0.49 & 68.0 & 64.8 & 62.0 & \multirow{4}{*}{$<0.001$} & 65.2 & 62.8 & 60.0 & \multirow{3}{*}{$<0.001$} \\
\hline NH-Black & 15.9 & 18.2 & 15.4 & & 15.6 & 15.4 & 15.5 & & 14.7 & 14.8 & 15.8 & \\
\hline Mexican- & 7 & 8.5 & 10.2 & & - & - & - & & - & - & - & \\
\hline \multicolumn{12}{|l|}{ American } & \\
\hline Hispanic & - & - & - & & 11.6 & 13.5 & 15.5 & & 14.3 & 15.6 & 17.1 & \\
\hline Other & 13.8 & 12.1 & 15.2 & & 4.8 & 6.2 & 7.1 & & 5.9 & 6.9 & 7.1 & \\
\hline \multicolumn{13}{|l|}{ Education (\%) } \\
\hline Less than HS & 34.1 & 30.2 & 23.1 & $<0.001$ & 26.1 & 22.0 & 18.6 & $<0.001$ & 22.7 & 18.3 & 23.0 & $<0.001$ \\
\hline $\begin{array}{l}\text { Completed } \\
\text { HS }\end{array}$ & 65.9 & 69.9 & 77.0 & & 73.9 & 78.0 & 81.4 & & 77.3 & 81.8 & 77.0 & \\
\hline
\end{tabular}

Estimates are weighted and based on data from three national surveys: National Health and Examination Survey (NHANES), National Health Interview Survey (NHIS), and Behavioral Risk Factor Surveillance System (BRFSS). P values are for $\chi^{2}$ tests. Percentages may not add up to 100 due to rounding NH non-Hispanic, HS high school

*The NHIS and BRFSS collected data that was representative of Hispanics during the study period, while the NHANES only collected representative information for Mexican-Americans

Moreover, there was a decrease in the proportion who met dietary guidelines for saturated fats ( 45.3 to $38.8 \%, P=0.03$ for trend) and sodium (33.5 to $28.2 \%, P=0.01$ trend) and no change for those who met targets for fiber and dietary cholesterol intake. Only about 4-5\% of adults with diabetes met all four of these dietary guidelines; this figure did not change during the study period.

Observed trends were generally similar after adjusting for sociodemographic characteristics (Appendix 2).

\section{Trends Across Subgroups}

Changes in diabetes management varied considerably across education (Appendix 3). Most notably, those who did not complete high school had substantially larger increases than their counterparts in the attainment of glycemic and blood pressure control $(P=0.02$ and 0.004 , respectively, for year by education interaction). Less educated adults with diabetes also had larger improvements in aerobic activity but smaller improvements for three preventive practices (pneumonia vaccination, $\mathrm{HbA} 1 \mathrm{c}$ testing, and diabetes education). Across race/ethnicity, trends were mostly consistent across groups, with several exceptions (Appendix 4). In particular, the use of antidiabetic medication among those with uncontrolled diabetes grew significantly faster for non-Hispanic Whites compared to racial/ethnic minorities $(P=0.04$ for year by race interaction). However, racial/ethnic minorities had larger gains than non-Hispanic Whites in aerobic activity. Trends for preventive practices were mixed; non-Hispanic Whites had larger increases than non-Whites in the engagement of three preventive practices (foot examinations, hepatitis $\mathrm{B}$ vaccination, and diabetes education), but smaller increases in two (influenza and pneumonia vaccinations).

\section{DISCUSSION}

From 1999 to 2016, the proportion of US adults with diabetes meeting recommendations for blood pressure, LDL cholesterol, medication usage, physical activity, and preventive practices increased substantially. However, the proportion attaining dietary goals stagnated and declined, while the proportion attaining glycemic control followed a quadratic trend, rising from 1999 to 2010 before declining somewhat from 2010 to 2016.

Much of the findings here align with past work..$^{8-12,15}$ For instance, one study showed that the proportion of US adults with diabetes attaining blood pressure and lipid control increased by 11.7 and 20.8 percentage points, respectively, from 1999 to $2010{ }^{8}$ There were, however, two exceptions. First, while existing research generally finds consistent improvements in glycemic control since the late 1990s. ${ }^{3,8,9}$ this paper is among the first to document a quadratic trend. This may stem from differences in data and methodology, as we used more recent national data and explicitly tested nonlinear trends. For example, a recent study using the NHANES observed similar rates of glycemic control from 1999 to 2014 among US adults, though it did not test for nonlinearities. ${ }^{10}$ Second, one of the few studies on trends in physical activity reported no change in aerobic activity among US adults with diabetes. ${ }^{16}$ That paper, however, examined a much shorter time interval and fewer time points, which may have limited its ability to detect secular trends.

The partial reversal in glycemic control is an important concern, given the well-documented link between hyperglycemia and diabetic complications. ${ }^{5}$ In fact, there is evidence that this trend may already be having an adverse impact on a population level. Recent analyses of US adults with diabetes, 
Table 3 Trends in the Attainment of Diabetes Management Targets Among US Adults with Diagnosed Diabetes, 1999-2004 to 2011-2016

\begin{tabular}{|c|c|c|c|c|c|c|}
\hline \multirow[t]{2}{*}{ Management outcomes } & \multirow{2}{*}{$\frac{1999-2004}{\%(95 \mathrm{CI})}$} & \multirow{2}{*}{$\frac{2005-2010}{\%(95 \mathrm{CI})}$} & \multirow{2}{*}{$\frac{2011-2016}{\%(95 \mathrm{CI})}$} & \multirow{2}{*}{$\begin{array}{l}P \text { value for } \\
\text { linear trend* }\end{array}$} & \multirow{2}{*}{$\begin{array}{l}P \text { value for } \\
\text { quad. trend* }\end{array}$} & \multirow{2}{*}{$\begin{array}{l}\text { Absolute change } \\
1999-2004 \text { to } 2011- \\
2016(95 \% \text { CI) }\end{array}$} \\
\hline & & & & & & \\
\hline \multicolumn{7}{|l|}{$\mathrm{ABC}$ targets } \\
\hline $\mathrm{HbA} 1 \mathrm{c}<7.0 \%$ & $\begin{array}{l}49.6(45.3- \\
53.9)\end{array}$ & $\begin{array}{l}58.6(55.2- \\
62.0)\end{array}$ & $\begin{array}{l}55.8(52.6- \\
58.9)\end{array}$ & 0.02 & 0.001 & $6.2(0.9-11.5)$ \\
\hline $\begin{array}{l}\text { Blood pressure < 140/ } \\
90 \mathrm{mmHg}\end{array}$ & $\begin{array}{l}66.8(63.3- \\
70.4)\end{array}$ & $\begin{array}{l}70.6(68.0- \\
73.2)\end{array}$ & $\begin{array}{l}73.4(70.5- \\
76.3)\end{array}$ & 0.002 & 0.06 & $6.6(2.0-11.1)$ \\
\hline $\begin{array}{l}\text { LDL cholesterol }<100 \mathrm{mg} / \\
\mathrm{dl}^{\dagger}\end{array}$ & $\begin{array}{l}37.5(31.7- \\
43.4)\end{array}$ & $\begin{array}{l}55.4(51.1- \\
59.7)\end{array}$ & $\begin{array}{l}56.3(51.7- \\
60.8)\end{array}$ & $<0.001$ & 0.02 & $18.7(11.3-26.1)$ \\
\hline All 3 ABC targets attained & $\begin{array}{l}13.3(9.8- \\
16.7)\end{array}$ & $\begin{array}{l}24.8(20.6- \\
29.1)\end{array}$ & $\begin{array}{l}20.2(15.7- \\
24.8)\end{array}$ & 0.08 & 0.002 & $7.0(1.3-12.7)$ \\
\hline \multicolumn{7}{|l|}{ Medication usage } \\
\hline Antidiabetic medication & $\begin{array}{l}82.5(78.3- \\
86.7)\end{array}$ & $\begin{array}{l}88.1(85.6- \\
90.5)\end{array}$ & $\begin{array}{l}91.1(88.8- \\
93.4)\end{array}$ & $<0.001$ & 0.57 & $8.6(3.8-13.3)$ \\
\hline Antihypertensive medication & $\begin{array}{l}81.6(78.7- \\
84.5)\end{array}$ & $\begin{array}{l}87.2(85.0- \\
89.4)\end{array}$ & $\begin{array}{l}86.6(84.0- \\
89.1)\end{array}$ & 0.007 & 0.001 & $5.0(1.1-8.8)$ \\
\hline Statin medication & $\begin{array}{l}31.9(28.5- \\
35.4)\end{array}$ & $\begin{array}{l}50.0(47.5- \\
52.5)\end{array}$ & $\begin{array}{l}55.9(52.6- \\
59.2)\end{array}$ & $<0.001$ & $<0.001$ & $24.0(19.2-28.7)$ \\
\hline \multicolumn{7}{|l|}{ Physical activity targets } \\
\hline \multicolumn{7}{|l|}{$\begin{array}{l}\text { Aerobic activity } \\
<10 \mathrm{~min} / \text { week }\end{array}$} \\
\hline$<10 \mathrm{~min} /$ week & $\begin{array}{l}55.7(54.5- \\
56.9)\end{array}$ & $\begin{array}{l}53.1(51.9- \\
54.3)\end{array}$ & $\begin{array}{l}48.6(47.6- \\
49.6)\end{array}$ & $<0.001$ & 0.37 & $-7.1(-8.7--5.5)$ \\
\hline$\geq 150 \mathrm{~min} /$ week & $\begin{array}{l}27.5(26.4 \\
28.5)\end{array}$ & $\begin{array}{l}28.5(27.3- \\
29.6)\end{array}$ & $\begin{array}{l}30.9(30.0- \\
31.8)\end{array}$ & $<0.001$ & 0.82 & $3.4(2.0-4.8)$ \\
\hline \multicolumn{7}{|l|}{ Strength training } \\
\hline$\geq 2$ times/week & $9.8(9.1-10.5)$ & $\begin{array}{l}11.6(10.9- \\
12.3)\end{array}$ & $\begin{array}{l}13.0(12.3- \\
13.6)\end{array}$ & $<0.001$ & 0.31 & $3.2(2.2-4.1)$ \\
\hline $\begin{array}{l}\text { Both physical activity targets } \\
\text { attained }\end{array}$ & $6.6(6.0-7.2)$ & $7.9(7.3-8.5)$ & $8.7(8.1-9.2)$ & $<0.001$ & 0.29 & $2.1(1.2-2.9)$ \\
\hline \multicolumn{7}{|l|}{ Preventive practices } \\
\hline \multicolumn{7}{|l|}{ Examinations } \\
\hline Dental (annual) & $\begin{array}{l}51.5(50.3- \\
52.7)\end{array}$ & $\begin{array}{l}52.3(51.2- \\
53.5)\end{array}$ & $\begin{array}{l}54.2(53.2- \\
55.2)\end{array}$ & $<0.001$ & 0.07 & $2.7(1.1-4.2)$ \\
\hline Foot (annual) & $\begin{array}{l}67.6(66.9- \\
68.2)\end{array}$ & $\begin{array}{l}70.8(70.3- \\
71.3)\end{array}$ & $\begin{array}{l}73.0(72.6- \\
73.4)\end{array}$ & $<0.001$ & 0.41 & $5.4(4.7-6.2)$ \\
\hline Eye (annual/biennial) $)^{\S}$ & $\begin{array}{l}77.6(75.4- \\
79.7)\end{array}$ & $\begin{array}{l}75.9(73.5- \\
78.3)\end{array}$ & $\begin{array}{l}78.9(77.0- \\
80.8)\end{array}$ & 0.18 & 0.12 & $1.3(-1.5-4.1)$ \\
\hline \multicolumn{7}{|l|}{ Vaccinations } \\
\hline Influenza (annual) & $\begin{array}{l}53.4(52.3- \\
54.5)\end{array}$ & $\begin{array}{l}54.4(53.3- \\
55.6)\end{array}$ & $\begin{array}{l}61.1(60.2- \\
62.0)\end{array}$ & $<0.001$ & 0.005 & $7.7(6.2-9.2)$ \\
\hline Pneumococcal (ever) & $\begin{array}{l}39.8(38.7- \\
40.9)\end{array}$ & $\begin{array}{l}44.9(43.7- \\
46.0)\end{array}$ & $\begin{array}{l}51.4(50.5- \\
52.3)\end{array}$ & $<0.001$ & 0.77 & $11.6(10.1-13.0)$ \\
\hline Hepatitis B (ever) & $\begin{array}{l}16.2(15.3- \\
17.2)\end{array}$ & $\begin{array}{l}20.1(19.2- \\
20.9)\end{array}$ & $\begin{array}{l}23.3(22.5- \\
24.1)\end{array}$ & $<0.001$ & 0.004 & $7.1(5.8-8.3)$ \\
\hline HbA1c test (biannual) & $\begin{array}{l}69.9(69.2- \\
70.6)\end{array}$ & $\begin{array}{l}71.8(71.3- \\
72.3)\end{array}$ & $\begin{array}{l}73.7(73.2- \\
74.1)\end{array}$ & $<0.001$ & 0.29 & $3.8(2.9-4.6)$ \\
\hline Diabetes education (ever) & $\begin{array}{l}51.9(51.2- \\
52.6)\end{array}$ & $\begin{array}{l}54.5(54.0- \\
55.0)\end{array}$ & $\begin{array}{l}52.9(52.5- \\
53.4)\end{array}$ & $<0.001$ & $<0.001$ & $1.0(0.2-1.9)$ \\
\hline \multicolumn{7}{|l|}{ Dietary targets } \\
\hline from saturated fats & $49.5)$ & $41.2)$ & $\begin{array}{l}50.0(35.3- \\
42.4)\end{array}$ & 0.03 & 0.50 & $-0.3(-12.010-$ \\
\hline$<2300 \mathrm{mg}$ sodium/day & $\begin{array}{l}33.5(30.5- \\
36.4)\end{array}$ & $\begin{array}{l}30.6(27.9- \\
33.2)\end{array}$ & $\begin{array}{l}28.2(25.2- \\
31.3)\end{array}$ & 0.01 & 0.52 & $-5.2(-9.4$ to -1.0$)$ \\
\hline$\geq 14 \mathrm{~g}$ fiber $/ 1000 \mathrm{kcal}$ & $\begin{array}{l}14.1(11.2- \\
17.0)\end{array}$ & $\begin{array}{l}12.9(10.4- \\
15.5)\end{array}$ & $\begin{array}{l}13.6(11.3- \\
15.9)\end{array}$ & 0.61 & 0.39 & $-0.5(-4.2-3.2)$ \\
\hline$<300 \mathrm{mg}$ cholesterol/day & $\begin{array}{l}66.4(62.8- \\
70.0)\end{array}$ & $\begin{array}{l}63.9(60.6- \\
67.2)\end{array}$ & $\begin{array}{l}64.7(61.6- \\
67.8)\end{array}$ & 0.82 & 0.46 & $-1.7(-6.4-3.0)$ \\
\hline All 4 dietary targets attained & $4.3(2.8-5.9)$ & $3.5(2.4-4.6)$ & $5.2(3.6-6.8)$ & 0.29 & 0.36 & $0.9(-1.3-3.1)$ \\
\hline
\end{tabular}

Estimates are weighted and based on pooled data from three national surveys: National Health and Examination Survey (NHANES), National Health Interview Survey (NHIS), and Behavioral Risk Factor Surveillance System (BRFSS). The NHANES was used for ABC, medication usage, and dietary targets, the NHIS for physical activity and preventive practices targets, and the BRFSS for preventive practices targets

*Using unpooled data, P values were calculated with logistic regression models where survey year was entered as a linear and quadratic term, respectively

†Estimates for LDL cholesterol levels were derived from a random morning fasting half-sample using Friedewald's formula

tEstimates only included respondents who were eligible for each class of medication, as described in existing ADA guidelines (see Appendix for more detail). Antidiabetic medication usage included respondents with uncontrolled diabetes (HbAlc $\geq 7.0 \%)$. Antihypertensive medication included respondents with hypertension (self-reported or blood pressure $\geq 140 / 90 \mathrm{mmHg}$ ). Statin medication usage included respondents who were age 40 or older or had cardiovascular disease or risk factors

${ }^{\S}$ Respondents were classified as meeting this recommendation if they (a) had retinopathy and received an annual eye examination or (b) did not have retinopathy and received a biennial eye examination 

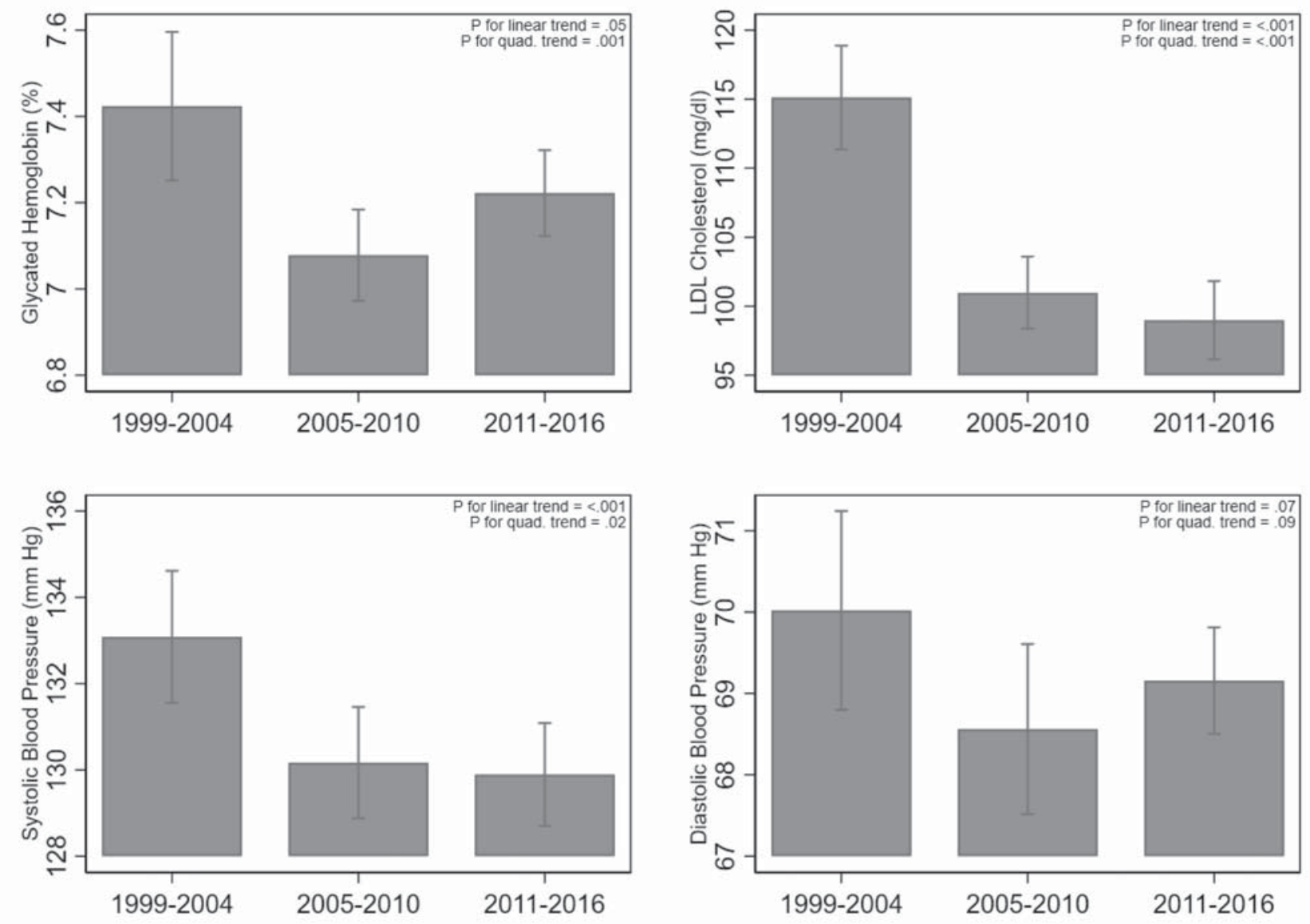

Figure 1 Mean glycated hemoglobin, low-density lipoprotein cholesterol, systolic blood pressure, and diastolic blood pressure among US adults with diagnosed diabetes, 1999-2016. This figure shows mean HbA1c (top left), LDL cholesterol (top right), systolic blood pressure (bottom left), and diastolic blood pressure (bottom right) for US adults with diagnosed diabetes at three consecutive time periods (1999-2004, 2005-2010, and 2011-2016). Estimates are weighted and come from pooled data using the National Health and Nutrition Examination Study. $P$ values are for linear regression models where data was unpooled and time was entered as a linear and quadratic term, respectively. Estimates for LDL cholesterol levels were derived from a random subsample of fasting respondents using Friedewald's formula.

for instance, showed that after declining steadily from 1999 to 2010 , rates of amputations and hyperglycemic emergencies have increased from 2010 to $2015 .^{23}$ Changes in the characteristics of adults with diabetes may have contributed to the decline in glycemic control, although observed trends did not change after adjusting for sociodemographic factors. It is also possible that physicians may be deintensifying treatment, unintentionally leading to higher levels of glycemia. Unfortunately, rigorously testing mechanisms were outside of the scope of this paper and should be the focus of future research.

Likewise, the lack of progress related to dietary guidelines is discouraging because proper nutrition is important for weight management, which has been associated with a host of health benefits for individuals with diabetes. ${ }^{24-26}$ Some suggest that individuals with diabetes may lack knowledge about the benefits of proper nutrition ${ }^{27,28}$ or may not receive clear guidance from health care providers. ${ }^{29,30}$ Others speculate that the difficulty of sustaining lifestyle changes compared to other types of therapy, in particular medication, may explain the low adherence to dietary guidelines. ${ }^{31}$ Related to this, some qualitative research suggests that the availability of medication may lead some patients to disregard the importance of nutrition. ${ }^{32}$ Identifying and subsequently mitigating the factors responsible for the decreased adherence to dietary goals may improve eating habits for adults with diabetes.

In contrast, the gains in blood pressure and lipid control, medication usage, and physical activity are encouraging signs of progress. Evidence from clinical trials has shown that reaching these targets can substantially mitigate health complications associated with diabetes. ${ }^{6,33-39}$ Several factors may explain these gains, including the dissemination of findings from landmark studies, increased awareness around the benefits of lifestyle modification and cardiovascular risk factor control, and the growing adoption of multi-faceted disease management programs by health systems. These trends are also likely inter-related; the rise in statin usage observed here, for example, likely accounts for much of the improvement in lipid control. 
It remains unclear whether preventive practices directly reduce the risk of diabetic health complications. Nonetheless, increased engagement in these behaviors may still represent important progress. These gains, for instance, may signal that US adults are becoming increasingly knowledgeable of and proactive in managing their diabetes. Growing engagement in preventive practices may also translate into improved relations between patients and their diabetes care team, as this offers more opportunities for the two to communicate and collaborate.

This study observed important reductions in social disparities in diabetes management. In particular, the attainment of glycemic and blood pressure control grew significantly faster for less educated adults compared to their peers. We found some evidence that this convergence may be related to larger improvements in lifestyle factors, as adherence to physical activity recommendations rose faster for less educated adults. Surprisingly, medication usage did not appear to contribute to the reduction of educational disparities, as the use of antidiabetic and antihypertensive grew at roughly the same rate across educational level.

Nevertheless, some disparities persisted and worsened over time. Most notably, the use of antidiabetic medication among those with uncontrolled diabetes grew significantly faster for non-Hispanic Whites compared to racial/ethnic minorities. This finding is consistent with past studies on the general adult population, which also find slower growth in the usage of prescription medication among some minority groups. ${ }^{40} \mathrm{Ad}-$ dressing this gap may be especially relevant moving forward, as the prevalence of diabetes continues to grow significantly faster for minorities. ${ }^{1-4}$ Moreover, newer classes of antidiabetic medications now offer additional benefits (e.g., protection against cardiovascular and kidney disease) ${ }^{41}$, suggesting that antidiabetic medication disparities may impact racial/ ethnic differences in areas other than glycemic control.

This paper had several notable strengths. In particular, the use of recent nationally representative data from three different surveys to examine five domains of diabetes management makes this one of the most comprehensive and up-to-date assessments of diabetes care available.

At the same time, this study had several important limitations. First, this study focused on standard, rather than individualized, treatment goals, since the latter is difficult to accurately obtain within national surveys. Second, the NHIS only focused on physical activity performed for leisure, excluding physical activity performed in other settings (e.g., work). Third, dietary, physical activity, and preventive practice measures were based on self-reported data, making them susceptible to problems such as social desirability bias. Fourth, because the BFRSS underwent significant changes in data collection in 2010, prevalence rates before and after this period may not be directly comparable ${ }^{20}$. Fifth, while we used recent guidelines to define therapeutic targets, it is important to note these changed over the study period, potentially impacting the comparability of adherence across time. Sixth, because we could not accurately distinguish between type 1 and type 2 diabetes, the trends reported here reflect a combination of both groups' health status.

In conclusion, there were marked improvements in across a broad range of diabetes management from 1999 to 2016 among US adults. Nonetheless, some gains in glycemic control were lost, and the attainment of dietary targets did not improve over time. Therefore, while much progress has been made, there are still critical gaps in diabetes care.

Acknowledgments: The author thanks Dr. Elizabeth Selvin for sharing her NHANES dataset that contained calibrated values for HbAlc.

Corresponding Author: Michael Fang, $\mathrm{PhD}$; Welch Center for Prevention, Epidemiology, and Clinical Research Johns Hopkins University, 2024 E Monument St, Baltimore, MD 21205, USA (e-mail: mfang9@jhu.edu).

Funding Information Dr. Fang was supported by NIH/NHLBI grant T32 HL0O7024.

\section{Compliance with Ethical Standards:}

Conflict of Interest: The author declares that he does not have a conflict of interest.

\section{REFERENCES}

1. Menke A, Casagrande S, Geiss L, Cowie CC. Prevalence of and trends in diabetes among adults in the United States, 1988-2012. JAMA. 2015;314(10):1021-1029.

2. Geiss LS, Wang J, Cheng YJ, et al. Prevalence and incidence trends for diagnosed diabetes among adults aged 20 to 79 years, United States, 1980-2012. JAMA. 2014;312(12):1218-1226.

3. Selvin E, Parrinello CM, Sacks DB, Coresh J. Trends in Prevalence and Control of Diabetes in the United States, 1988-1994 and 1999-2010. Ann Intern Med. 2014;160(8):517-525.

4. Fang M. Trends in the prevalence of diabetes among US Adults: 19992016. Am J Prev Med. 2018;55(4):497-505.

5. Fowler MJ. Microvascular and macrovascular complications of diabetes. Clin Diabetes. 2008;26(2):77-82.

6. Zoungas S, Arima $\mathbf{H}$, Gerstein $\mathbf{H C}$, et al. Effects of intensive glucose control on microvascular outcomes in patients with type 2 diabetes: a meta-analysis of individual participant data from randomised controlled trials. Lancet Diabetes Endocrinol. 2017;5(6):431-437.

7. American Diabetes Association. American Diabetes Association Stan dards of Medical Care in Diabetes-2016. 2016;34(Supp 1):S1-S112.

8. Ali MK, Bullard KM, Saaddine JB, Cowie CC, Imperatore G, Gregg EW. Achievement of goals in US diabetes care, 1999-2010. $N$ Engl $J$ Med. 2013;368(17): 1613-1624.

9. Casagrande SS, Fradkin JE, Saydah SH, Rust KF, Cowie CC. The prevalence of meeting AlC, blood pressure, and LDL goals among people with diabetes, 1988-2010. Diabetes Care. 2013;36(8):2271-2279.

10. Carls G, Huynh J, Tuttle E, Yee J, Edelman SV. Achievement of glycated hemoglobin goals in the US remains unchanged through 2014. Diabetes Therapy. 2017;8(4):863-873.

11. Kazemian P, Shebl FM, McCann N, Walensky RP, Wexler DJ. Evaluation of the cascade of diabetes care in the United States, 20052016. JAMA Intern Med. 2019;179(10):1376-1385.

12. Mann DM, Woodward M, Ye F, Krousel-Wood M, Muntner P. Trends in medication use among US adults with diabetes mellitus: glycemic control at the expense of controlling cardiovascular risk factors. Arch Intern Med. 2009;169(18):1718-1725.

13. Alexander GC, Sehgal NL, Moloney RM, Stafford RS. National trends in treatment of type 2 diabetes mellitus, 1994-2007. Arch Intern Med. 2008;168(19):2088-2094. 
14. Centers for Disease Control and Prevention. Diabetes Report Card 2017. Atlanta, GA: Centers for Disease Control and Prevention, US Department of Health and Human Services; 2018.

15. Casagrande $\mathbf{S}$, Cowie $\mathbf{C}$. Trends in dietary intake among adults with type 2 diabetes: NHANES 1988-2012. J Hum Nutr Diet. 2017;30(4):479-489.

16. Zhao G, Ford E, Li C, Mokdad A. Compliance with physical activity recommendations in US adults with diabetes. Diabet Med. 2008;25(2):221-227.

17. Oza-Frank R, Cheng YJ, Narayan KV, Gregg EW. Trends in nutrient intake among adults with diabetes in the United States: 1988-2004. J Acad Nutr Diet. 2009; 109(7):1173-1178.

18. Zipf G, Chiappa M, Porter KS, Ostchega Y, Lewis BG, Dostal J. Health and nutrition examination survey plan and operations, 1999-2010. Vital Health Stat. 2013;1(56): 10-22.

19. Parsons VL, Moriarity CL, Jonas K, Moore TF, Davis KE, Tompkins L. Design and estimation for the national health interview survey, 20062015. Vital Health Stat. 2014;2(165): 1-53.

20. Center for Disease Control and Prevention. Behavioral Risk Factor Surveillance System Overview: BRFSS 2016. 2017; https://www.cdc. gov/brfss/annual_data/2016/pdf/overview_2016.pdf. Accessed March 30, 2018.

21. Johnson CL, Paulose-Ram R, Ogden CL, et al. National health and nutrition examination survey. Analytic guidelines, 1999-2010. Vital Health Stat 2. 2013(161):1-24.

22. Ingram D, Malec D, Makuc D, et al. National Center for Health Statistics Guidelines for Analysis of Trends. Vital Health Stat. 2018;2(179):1-71.

23. Gregg EW, Hora I, Benoit SR. Resurgence in Diabetes-Related Complications. JAMA. 2019;321(19):1867-1868.

24. Evert AB, Boucher JL, Cypress M, et al. Nutrition therapy recommendations for the management of adults with diabetes. Diabetes Care. 2014;37(Supplement 1):S120-S143.

25. Ley SH, Hamdy O, Mohan V, Hu FB. Prevention and management of type 2 diabetes: dietary components and nutritional strategies. Lancet. 2014;383(9933): 1999-2007.

26. Ajala O, English P, Pinkney J. Systematic review and meta-analysis of different dietary approaches to the management of type 2 diabetes. Am J Clin Nutr. 2013;97(3):505-516.

27. Ahola A, Groop PH. Barriers to self-management of diabetes. Diabet Med. 2013;30(4):413-420.

28. Nagelkerk J, Reick K, Meengs L. Perceived barriers and effective strategies to diabetes self-management. J Adv Nurs. 2006;54(2):151-158.

29. Lianov L, Johnson M. Physician competencies for prescribing lifestyle medicine. JAMA. 2010;304(2):202-203.

30. Kahan S, Manson JE. Nutrition counseling in clinical practice: how clinicians can do better. JAMA. 2017;318(12):1101-1102

31. Vijan S, Stuart N, Fitzgerald $\mathbf{J}$, et al. Barriers to following dietary recommendations in Type 2 diabetes. Diabet Med. 2005;22(1):32-38.

32. Booth AO, Lowis C, Dean M, Hunter SJ, McKinley MC. Diet and physical activity in the self-management of type 2 diabetes: barriers and facilitators identified by patients and health professionals. Prim Health Care Res Dev. 2013;14(3):293-306.

33. Colberg SR, Sigal RJ, Yardley JE, et al. Physical activity/exercise and diabetes: a position statement of the American Diabetes Association. Diabetes Care. 2016;39(11):2065-2079.

34. UK Prospective Diabetes Study Group. Effect of intensive blood-glucose control with metformin on complications in overweight patients with type 2 diabetes (UKPDS 34). Lancet. 1998;352(9131):854-865.

35. UK Prospective Diabetes Study Group. Tight blood pressure control and risk of macrovascular and microvascular complications in type 2 diabetes: UKPDS 38. BMJ. 1998;317(7160):703.

36. Brunström M, Carlberg B. Effect of antihypertensive treatment at different blood pressure levels in patients with diabetes mellitus: systematic review and meta-analyses. BMJ. 2016;352:i717.

37. UK Prospective Diabetes Study Group. Intensive blood-glucose control with sulphonylureas or insulin compared with conventional treatment and risk of complications in patients with type 2 diabetes (UKPDS 33). Lancet. 1998;352(9131):837-853.

38. Emdin CA, Rahimi K, Neal B, Callender T, Perkovic V, Patel A. Blood pressure lowering in type 2 diabetes: a systematic review and metaanalysis. JAMA. 2015;313(6):603-615.

39. Kearney P, Blackwell L, Collins R, et al. Efficacy of cholesterol-lowering therapy in 18,686 people with diabetes in 14 randomised trials of statins: a meta-analysis. Lancet. 2008;371(9607):117-125.

40. Kantor ED, Rehm CD, Haas JS, Chan AT, Giovannucci EL. Trends in prescription drug use among adults in the United States from 19992012. JAMA. 2015;314(17):1818-1830.

41. Zelniker TA, Wiviott SD, Raz I, et al. Comparison of the Effects of Glucagon-Like Peptide Receptor Agonists and Sodium-Glucose Cotransporter 2 Inhibitors for Prevention of Major Adverse Cardiovascular and Renal Outcomes in Type 2 Diabetes Mellitus: Systematic Review and Meta-Analysis of Cardiovascular Outcomes Trials. Circulation. 2019;139(17):2022-2031.

Publisher's Note Springer Nature remains neutral with regard to jurisdictional claims in published maps and institutional affiliations. 